\title{
A Verbal Communication Game for Architecture, Engineering and Construction Students
}

\author{
Bakr M. Aly Ahmed \\ North Dakota State University \\ Khaled Nassar \\ American University in Cairo \\ Mike Christenson \\ North Dakota State University
}

\begin{abstract}
The ability to communicate effectively is of utmost importance in all professional fields. Effective communication skills are particularly important in architecture/engineering/construction (AEC) fields, where professionals need to communicate complex details and spatial relationships using written, graphical and verbal communication. While traditional curricula in AEC fields provide significant coverage of written and graphical communication skills, verbal communication skills are often limited to a dedicated course lacking discipline-specific content. In addition, there is a shortage of activities and tools to emphasize and develop verbal communication skills of AEC students. This paper presents a verbal communication game for students in the AEC fields. The game emphasizes the importance of clear, succinct verbal communication. The game is highly robust and can be adapted and carried out in a number of ways depending on situation and context.
\end{abstract}

\section{Introduction}

Effective communication skills are required in all aspects of contemporary life. ${ }^{1}$ In architecture/engineering/construction (AEC) fields, effective communication is not limited to the ways in which constituents communicate face-to-face with others, which necessarily involves aspects such as body and facial gestures; it also includes distance communications of workrelated details and spatial relationships requiring a high degree of accuracy and clarity.

Therefore, developing strong technical and practical communication skills is important for AEC students, particularly to prepare for the professional requirements of distance communication with clients, government officials, managers, supervisors, and construction crews within the professional arena.

Architecture students in particular rely heavily on verbal communication throughout their design processes. Although architectural design pedagogy is often conceived of as a visual, material, and/or spatial endeavor, verbal communication with student peers and studio leaders constitutes a critical component of the learning process. This is also generally true of architecture as a discipline and professional practice. ${ }^{2}$ AEC practice as it occurs in real-world situations relies on the use of artifacts (e. g., models, product samples, and drawings) to structure critically important verbal exchanges between and among constituents. ${ }^{3}$ 
Immersion in relevant situations and practice is an effective means of acquiring knowledge. However, AEC students often have few opportunities for direct exposure to practical issues involved with real-world construction management scenarios. Case studies in a classroom setting and construction site tours tend to be less interactive and efficient than the mode of learning-bydoing. These problems are not exclusive to AEC education, but shared by most higher-education models. ${ }^{4}$ Simulation gaming can be seen as a solution to the problem of direct exposure. Games allow for pedagogically useful verisimilitude, i. e., the degree to which a simulation depicts reality in the real world. ${ }^{5}$ For this reason, simulation gaming provides a means of experimenting with concepts and ideas that would otherwise be impractical. The pedagogical benefits of simulation gaming are widely established, as games have been shown to provide practical decision-making and management experiences to students. ${ }^{6,7,8}$ Simulation games immerse students in simulated environments where students can collaborate, compete, and create synthetic solutions for various situations utilizing techniques they learned in the classroom. ${ }^{9}$ Simulation gaming has been successfully presented across AEC curricula by researchers since the late 1960s in an effort to address certain basic skills that professionals should possess. ${ }^{10}$

The effectiveness of teaching via simulation games is usually very high as games provide a unique way to reinforce theory discussed in the classroom..$^{11}$ Moreover, gaming complements rather than substitutes for more formal pedagogical approaches: integrating standard formal teaching methods and simulation games as a laboratory to test and reinforce the relevance of theories can be a very effective teaching method. In particular, games have been shown to be more effective if they are embedded in instructional programs that include debriefing and feedback. ${ }^{12}$ Perhaps the most well-known communication game is the "Who are we?" game, designed around the principles of the Johari Window model developed by Dr. Joseph Luft and Dr. Harry Ingham. This model identifies sharing and feedback as the keys to building open communication. Open communication leads to a climate of trust and access to untapped possibilities. $^{13}$

In this paper, the authors introduce a discipline-specific communications game that emphasizes the importance of accurate, clear, succinct, and distinct distance communication skills. The authors describe the game intent and scenario, and the results of gameplay in the classroom. The authors briefly analyze the results and place them in the context of professional curricula. The authors conclude with comments on the potential of simulation games as curriculum evaluation tools.

\section{The Game}

\section{Game intent}

The authors designed a simulation game to help students develop and refine their verbal communication skills for the workplace, including teamwork and use of AEC terminology and technology. Unlike many communication exercises and skills developed in AEC curricula, the game focuses on everyday communication in the field. The game emphasizes the importance of communicating terms from geometry (e. g., "point," "line," "circle," "square," "triangle," 
“center," "tangent”), orientation (e. g., "start," "right," "left," “up," “down," “45-degree," "straight," "end"), materials (e. g., "glass," "wood," "concrete," "bars," "steel," "granite"), structures (e. g., "beam," "column," "arch," "frame," "Vierendeel," "girder," "gusset plate”), surfaces (e. g., "slab," "wall," "partition," "panel," "box"), and environmental control systems (e. g., "chiller," "boiler," "economizer," "AC," "WC," "PC," "cooling tower," "pipes," "ducts"), but is not limited to these terms.

In designing the game, the authors' approach was to 1) analyze sample situations involving decision-making; and 2) teach logical decision-making procedures. The game is designed to do this in a non-confrontational way on the basis of the following principles:

- $\quad$ keep it simple,

- use metaphors and analogy,

- $\quad$ use many different forums to spread the word,

- $\quad$ repeat key messages,

- $\quad$ lead by example,

- $\quad$ explicitly address inconsistencies,

- $\quad$ listen and be listened to.

\section{Game scenario}

As a focus group of AEC students, the authors selected a section of eighteen students from the second-year design studio in NDSU's professional architecture degree program. Teams of two students are formed in which one student assumes the role of a designer in a design office, and the other student assumes the role of a superintendent at a construction site. The teams compete against each other in an attempt to verbally communicate information. Specifically, the "designer" must communicate the floor plan drawing shown in the bottom of Figure 1 to the "superintendent," relying only on telephone (i. e., verbal) communication. (Figure 2.)

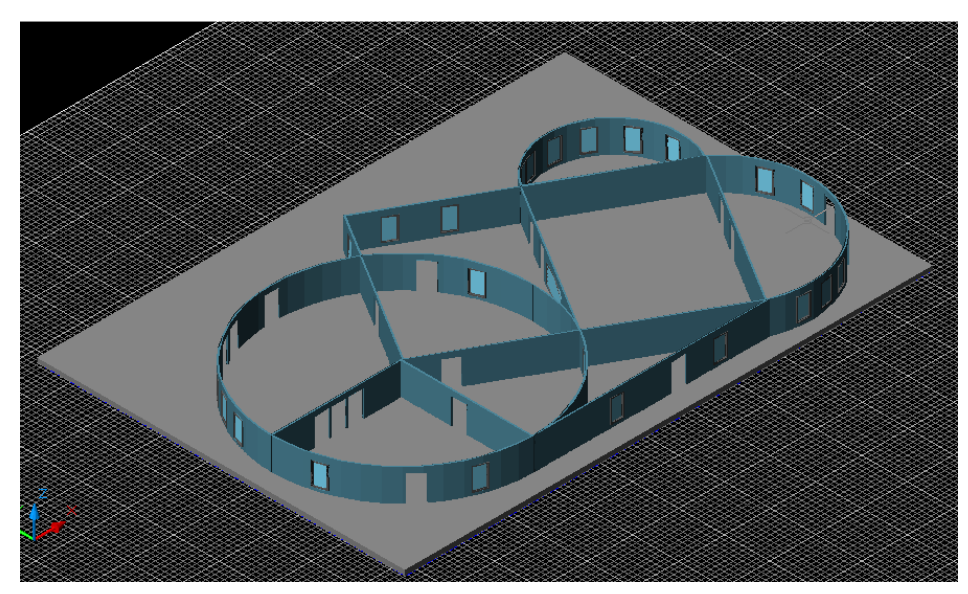




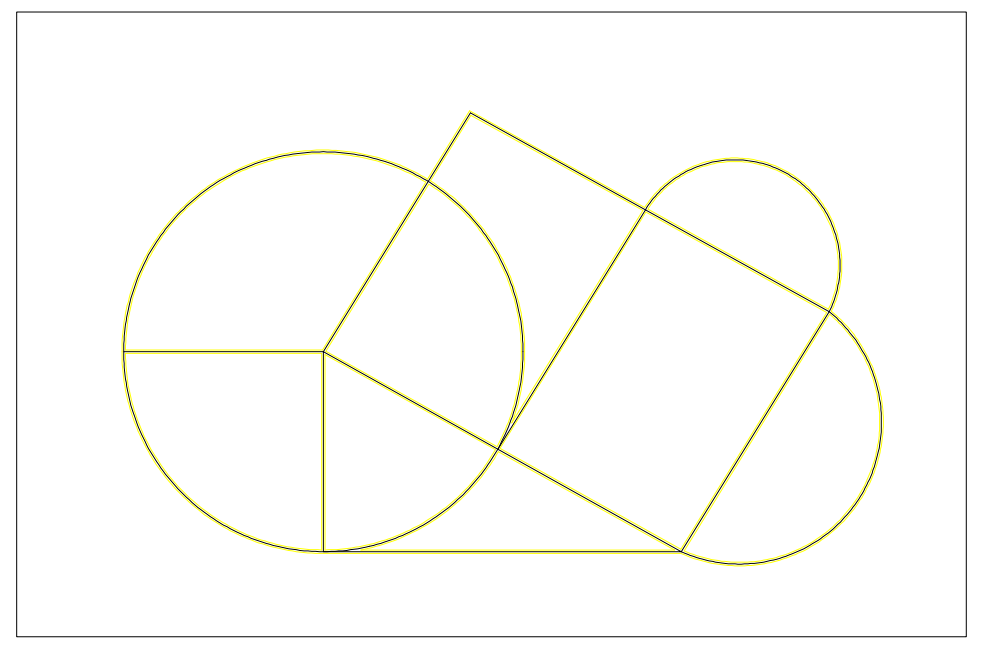

Figure 1. Digital model of building (top); floor plan of building (bottom). Not to scale.
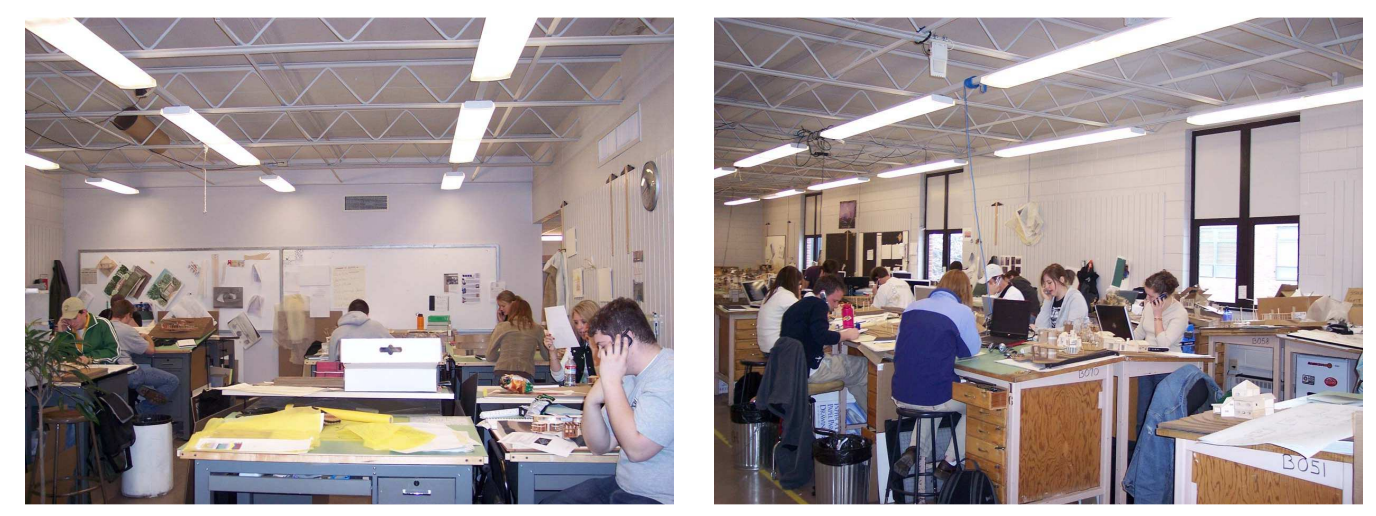

Figure 2. Architecture student teams in the process of playing the communication game: senders (left) and receivers (right).

\section{Game results}

Table 1 shows a sample of the results or the outcomes of the communicated information. Although all teams began with the same source (the floor plan shown in Figure 1), the results showed a wide range of accuracy. 
Table [1] Examples of game output

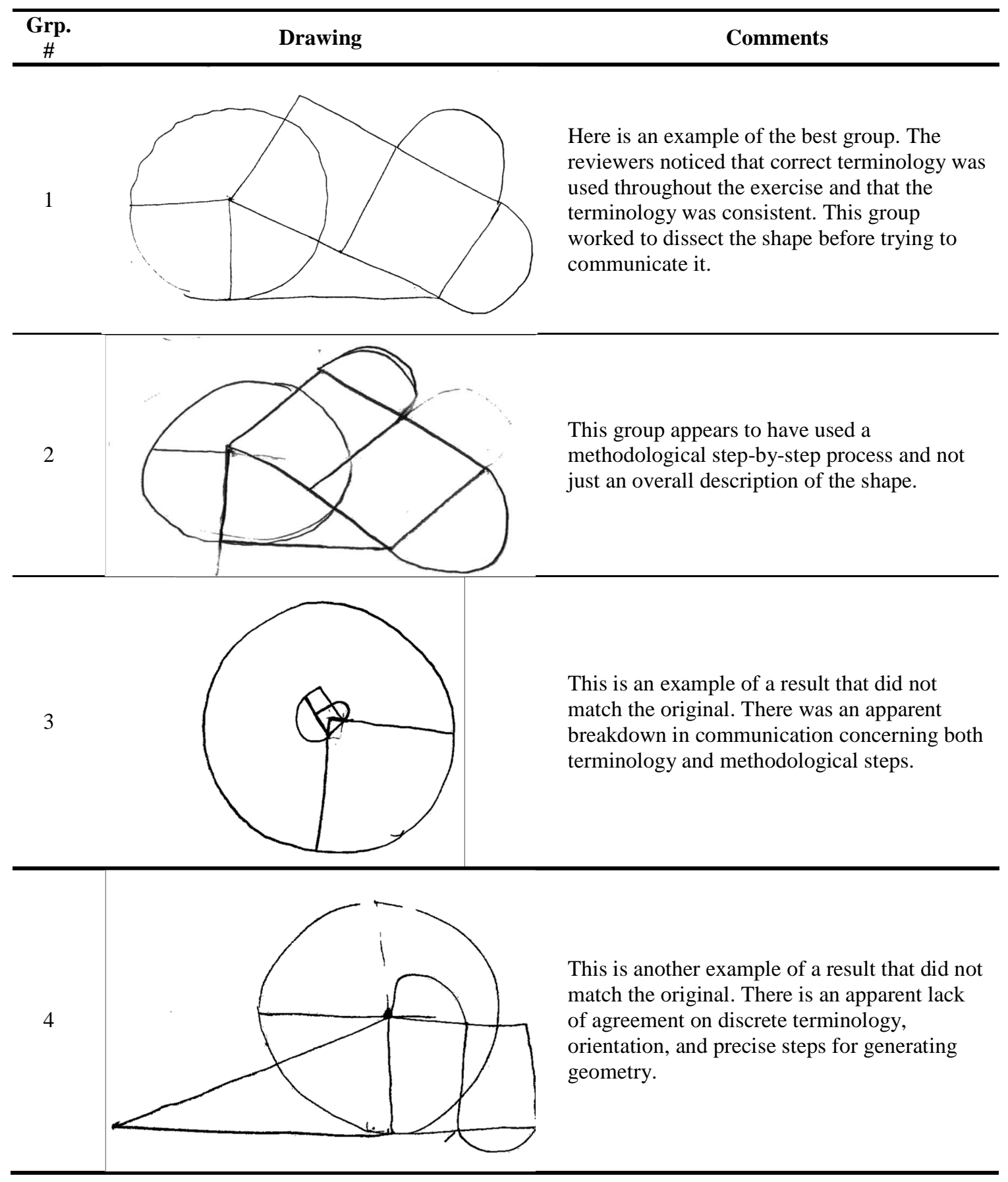

\section{The problem of perception}

Perception is the process by which individuals become aware of, organize, and interpret information received though their senses. The factors that shape students' perceptions are significant because they are at the heart of how successfully they communicate in encoding messages and improving both the clarity and the persuasiveness of their ideas. Relevant to the 
game described here, several questions need to be considered such as: What is the definition of students' perception? What are the major factors in perception that help explain why students perceive things differently/erroneously? What is the definition of self-concept, how does it relate to perception and communication, and what are some of the major barriers in forming an accurate self-concept? What are the barriers to accurate perception of others' ideas, and how does each barrier affect successful communication? What are the perceptual skills used to improve self-concept, and how are those skills used to improve others' perception? What perception skills covered in this exercise relate specifically to professional careers in AEC industries? ${ }^{14}$ Physiological factors (e. g., poor vision or hearing), psychological factors (e. g., emotions or outlook on life), and cultural factors (e. g., cultural heritage and values) are three factors causing people to perceive things differently and often erroneously. ${ }^{15}$

After analyzing the gameplay, accurate perception is clearly shown to be a factor in students' communication. There is obvious potential to improve the accuracy of students' self-concept and the perception of others by identifying perceptual mismatches behind miscommunication, and to develop the skills of self-reflection, mindfulness, and perception checking.

\section{Game Analysis and Discussion}

The game is a cycle of processing information, requiring a degree of clarity between the sender and the receiver, and based on knowledge that is acquired through the curriculum of core and support courses as shown in Figure 3. 


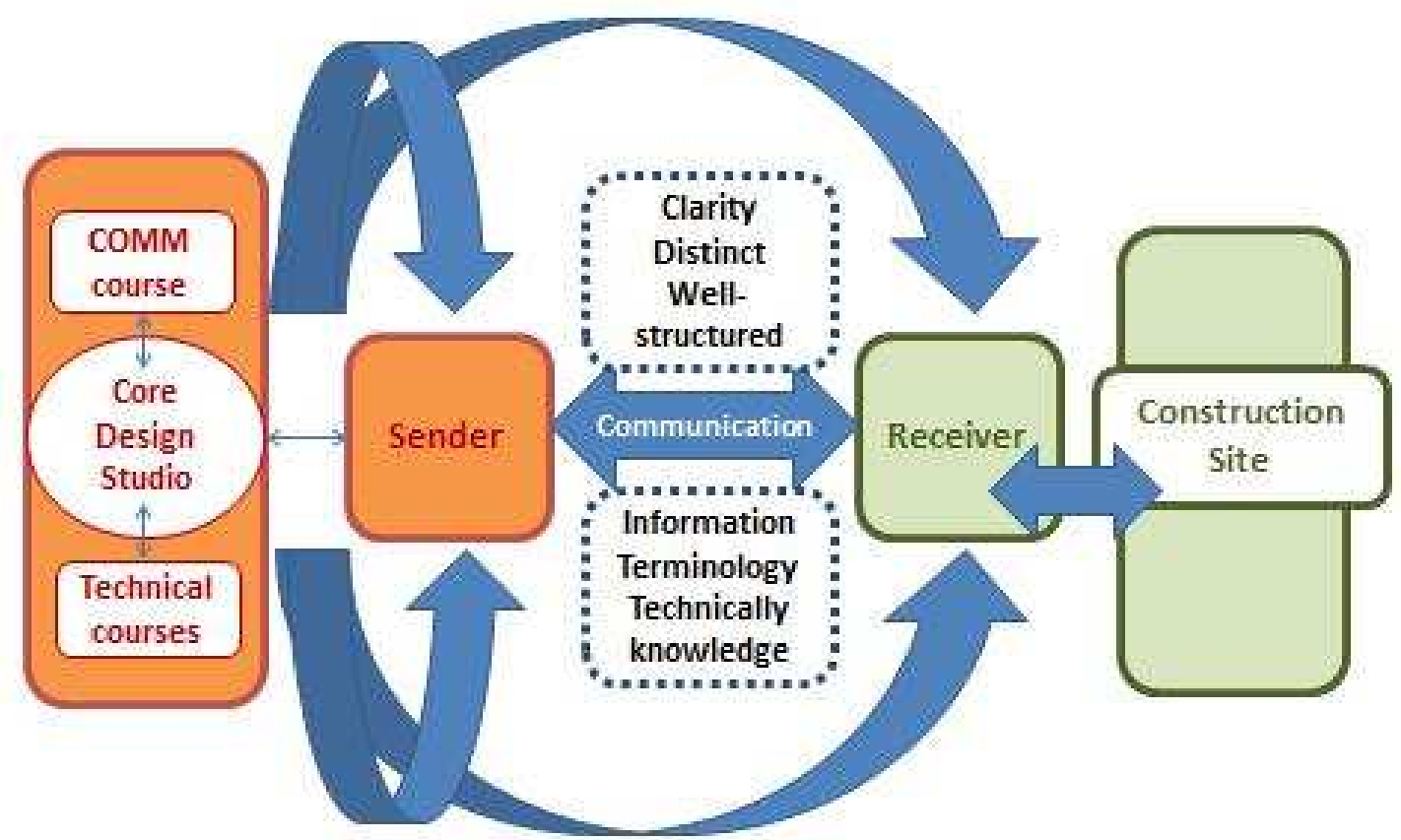

Figure 3. Communication at the center of an integrated curriculum.

Although written, graphical, and verbal communication skills are of paramount importance in AEC fields, dedicated communication courses in these fields are often limited to a speech or public speaking class, with content not connected or relevant to the core of the curriculum. AbouRizk and Sawhney point out that traditional teaching methods are not fully capable of providing AEC students with the necessary skills and knowledge to solve real world problems encountered in construction. ${ }^{16}$ This realization has moved several researchers to explore alternatives where learners can actively participate in the learning process, and to advocate the importance of problem-solving in environments where concepts are contextually embedded. Simulation gaming has emerged as an important approach to meet this need. However, simulation-based tools are greatly under-represented in AEC curricula. As an effort to address this issue, Park et al suggested factors for the implementation of simulation in the curriculum. ${ }^{17}$ They argue for greater emphasis on practical knowledge and efficient tools designed to enhance the students' thinking, problem-solving and interpersonal skills so that they can face professional challenges. Although the effectiveness of Park et al's proposed success factors needs to be further investigated by more industry-linked research and classroom applications, the findings obtained from this research provide useful guidelines for the development of simulation tools in AEC curricula.

\section{Future versions and enhancement}


This paper presents a model of a verbal communication game emphasizing the importance of clear, succinct verbal communication; however, the game is highly robust and can be adapted and carried out in a number of ways depending on the circumstances and the context. For example, there is potential for:

- One-to-one communication,

- One-to-many communication,

- Many-to-one communication, and

- Many-to-many communication.

Other options of possible communications include:

- One-way, two-sided,

- Two-way, two-sided,

- $\quad$ One-way, multiple-sided, and

- $\quad$ Two-way, multiple-sided.

\section{Conclusions}

In observed gameplay, almost $50 \%$ of the focus group failed to closely match the original drawing. This suggests the need to rethink how verbal communication skills are taught to AEC students. The authors recognize that there is currently a shortage of in-class activities and instructional exercises aimed at developing and improving verbal communication skills relevant to AEC fields.

There is potential for using verbal communication games as tools for evaluating the content of AEC communication courses, with the goal of improving their disciplinary relevancy. Overall, the authors identify the need for further development of discipline-specific communication courses for AEC students, incorporating discipline-specific terminology and technical content.

\footnotetext{
${ }^{1}$ Formby, C. (2007), “The Importance of Communication Skills.” At http://ezinearticles.com/?The-Importance-OfCommunication-Skills\&id=780635. Accessed July 31, 2013.

${ }^{2}$ Avidan, Y. and Goldschmidt, G. (2013), "Talking architecture: language and its roles in the architectural design process.” In Proceedings, ICoRD '13 (International Conference on Research into Design), Indian Institute of Technology Madras, Chennai, 7-9 January 2013. 10 pp.

${ }^{3}$ Luck, R. (2007), "Using artefacts to mediate understanding in design conversations." In Building Research \& Information, v. 35, no. 1

${ }^{4}$ Lee, N. and Rojas, E. (2010), "Innovative and transformative learning environments in construction engineering and management education," in Proceedings, 2010 ASEE Annual Conference, 11 pp.

${ }^{5}$ Keys, J. B. (1997), "Strategic management games: a review.” In Simulation \& Gaming v. 28, no. 4, 395-422

${ }^{6}$ Alarcon, L. F. and Ashley, D. B. (1999), "Playing games: evaluating the impact of lean production strategies on project cost and schedule." In Proceedings, 7th Annual Conference of the International Group for Lean Construction (IGLC-7), 26-28 July 1999, University of California, Berkeley, CA.

${ }^{7}$ Bichot, T. (2001), "The construction marketing game," unpublished masters thesis, Bradley University, Peoria, Illinois.
} 


\footnotetext{
${ }^{8}$ Nassar, K. (2001), "Managing construction equipment buy and sell decisions replacement: a simulation game." In Proceedings of the Thirty-Seventh Annual Conference, ASC, pp. 187-198.

${ }^{9}$ Ibid.

${ }^{10}$ Nassar, K. (2002), "Simulation gaming in construction: ER, the equipment replacement game.” Journal of Construction Education, v. 7, no. 1, pp. 16-30.

${ }^{11}$ Frazer, R. (1975), Business Decision Simulation. (Reston, VA: Reston Publishing Company.)

${ }^{12}$ Hays, R. T. (2005), "The effectiveness of instructional games: A literature review and discussion." (No.

NAWCTSD-TR-2005-004). Naval Air Warfare Center Training Systems Div., Orlando, FL.

${ }^{13}$ Luft, J. and Ingham, H. (1955), “The Johari window, a graphic model of interpersonal awareness.” In Proceedings of the Western Training Laboratory in Group Development. (Los Angeles: UCLA.)

${ }^{14}$ Hamilton, C. M. and Creel, B. (2011), Communicating for Success. (Boston: Allyn \& Bacon.)

${ }^{15}$ Ibid.

${ }^{16}$ AbouRizk, S. and Sawhney, A. (1994), "Simulation and gaming in construction engineering education." In Proceedings, ASEE/C2E2 /C2EI Conference, Edmonton, Alberta, Canada, American Society for Engineering Education.

${ }^{17}$ Park, M., Chan, S. L., and Ingawale-Verma, Y. (2003), "Three success factors for simulation based construction education." Journal of Construction Education, v. 8, no. 2, pp. 101-114.
} 